\title{
Development of New Hybrid Phoenix Pusilla/Carbon/Fish Bone Filler Reinforced Polymer Composites
}

\author{
Abhishek $S^{1}$, Sanjay M R ${ }^{1,2}$, Raji George ${ }^{1}$, Suchart Siengchin ${ }^{2}$, Jyotishkumar \\ Parameswaranpillai $^{3}$, Catalin Iulian Pruncu $^{4,5}$ \\ ${ }^{1}$ Department of Mechanical Engineering, Ramaiah Institute of Technology, Bangalore, \\ Karnataka, India. \\ ${ }^{2}$ Department of Mechanical and Process Engineering, The Sirindhorn International Thai-German \\ Graduate School of Engineering (TGGS), King Mongkut's University of Technology North \\ Bangkok, Bangkok, Thailand. \\ ${ }^{3}$ Center of Innovation in Design and Engineering for Manufacturing, King Mongkut's University \\ of Technology North Bangkok, Bangkok, Thailand. \\ ${ }^{4}$ Department of Mechanical Engineering, Imperial College London, Exhibition Rd., SW7 2AZ \\ London, UK. \\ ${ }^{5}$ Department of Mechanical Engineering, School of Engineering, University of Birmingham, B15 \\ 2TT, United Kingdom. \\ *Corresponding author: mrsanjay@msrit.edu
}




\begin{abstract}
Designing new eco-friendly fibers enable the creation of an alternative resource for many applications, specifically within the field of polymeric composites. This paper details the fabrication of hybrid epoxy composites comprising natural fiber, Phoenix Pusilla plant dry leaves which belong to the family of date palm and nanofillers made from the fish bones, which has been explored for the first time. ASTM standards provided the guidelines for the preparation of samples and mechanical measurements. The mechanical properties of the pure carbon fiber composites were compared with that of the hybrid composites containing carbon fiber, natural fiber and nanofiller. The results validate the potential of hybrid composites containing novel fibers. Adding the bio-nanofillers in hybrid polymer composites permits the enhancement of the tensile strength, flexural strength, and hardness by $22.5 \%, 200 \%, 100 \%$ and $15.2 \%$ respectively.

Keywords: Phoenix Pusilla, Nanofiller, Mechanical properties, Morphological Analysis
\end{abstract}




\section{Introduction}

The natural fibers reinforced with polymer matrix composite family have gained popularity as a result of key features including their lightweight, economic benefits, renewability, and ecofriendly characteristics $[1,2]$. In this context, the current research aims at investigating the mechanical and morphological characterisation of Phoenix Pusilla/carbon fiber reinforced composites with or without the bio-nanofillers. Through hybridisation of two or more natural fibers, fabrication of novel composites shows superior mechanical property and additional biodegradable characteristics, compared to the non-hybridised composites. The chemically treated kenaf/coir [3] and banana/kenaf fibers [4] reinforced composites prepared in 1:1 ratio shows an improvement in its mechanical and biodegradation properties. Jute/hemp/flax fibers reinforced hybrid composites possesses enhanced mechanical properties compared to the individual composites and other potential dual combinations (jute/hemp, hemp/flax, jute/flax) [5]. Additionally, the properties can be improved by hybridising the natural fibers with various synthetic fibers. Natural fibers hybridised with glass fibers illustrate improved water absorption behaviour [5]. On the other hand, jute fiber reinforced with glass fibers in equal proportion showed enhanced tensile property. voids are decreased by the addition of fillers to sisal/GFRP composites and addition of glass fiber improved mechanical property, thermal stability and water absorption properties [6-7].

The stability and bonding potency of the fiber and matrix is essential for the betterment of mechanical properties of the composites. The bonding between them could be increased by various chemical treatments such as $\mathrm{NaOH}$, acetylation, silane, stearic acid etc. $\mathrm{NaOH}$ treatment is a widely used treatment technique which can effectively removes the hemicellulose and lignin contents from the fiber surfaces and improves the bonding strength between fiber and matrix 
materials [8-13]. Some studies investigated the effect of different fillers such as bagasse fibre, carbon black, tungsten carbide, $\mathrm{CaCO}_{3}$ with jute fiber and synthetic fiber reinforced composites to enhance the tensile property [14-16]. In terms of reinforcing fibers for polymeric composites, the literature review noted that Phoenix Pusilla plant leaf fiber has not yet been applied in practice. Therefore, the present study focuses on the fabrication of the carbon/Phoenix Pusilla epoxy hybrid composites by the addition of fish bone nanopowders as a filler material to the matrix.

\section{Materials and Methods}

\section{Materials}

Phoenix Pusilla plant leaves were collected from, in Ammanaghatta village, Tumkur, Karnataka, India and dried under the sun light. After drying these leaves were treated with the $4 \% \mathrm{NaOH}$ for $1 \mathrm{~h}$ and were kept under the sun light for drying. After the treatment these leaves were used for the preparation of mats, it is done manually. The collected fish bones (Fish name: Gibelion Catla) were cleaned in hot water and followed by washing with the distilled water. The nanofiller material used in the present investigation is in the powder form of size $75 \mu \mathrm{m}$ made from the ball milling process. The resin and hardener used are Lapox L-12 and Lapox K-6 respectively. Table 1 presents details of their mechanical properties. Figure 1 illustrates the generic perspectives regarding the analysed materials.

\section{Fabrication of the Laminates}

The adaptation of laminate sequences including those with fillers and those without, enabled the fabrication of four individual categories of laminates. Finally, the carbon/Phoenix Pusilla hybrid composite laminates with/without the fillers are manufactured by the hand lay-up process $[6,7]$. The structural visual perspective of fabricated laminates is illustrated in Table 2. 


\section{Mechanical properties}

In order to comprehend specific aspects, mechanical characterisation has been conducted. Such aspects include tensile strength, flexural strength, inter laminar shear strength (ILSS), hardness and charpy impact strength of the composite specimens. Preparation has been conducted in accordance with ASTM D638-03, ASTM D790-07, ASTM D2344, ASTM E384 and ASTM D256-06 respectively. Testing was carried out according to the standards, in each scenario three trials were conducted and the average was reported. All tests were carried out at $26^{\circ} \mathrm{C}$ and at atmospheric pressure. Tensile property is tested in UTM at a loading rate of $2.0 \mathrm{~mm} / \mathrm{min}$, while flexural and ILSS tests were performed in the same machine at a loading rate of $2.5 \mathrm{~mm} / \mathrm{min}$ and $1.5 \mathrm{~mm} / \mathrm{min}$ respectively. Charpy impact test was conducted to evaluate the impact strength and the Vickers hardness test was used to evaluate the hardness of the laminates with a load rate of $60 \mu \mathrm{m} / \mathrm{sec}$, for a period of $15 \mathrm{~s}$ with a diamond indenter.

\section{Morphological Analysis}

Scanning electron microscopy (SEM) was operated with an accelerated voltage of $20 \mathrm{kV}$ and magnification of 300 times for visualization of tensile fractured specimens. In order to prevent the accumulation of electrical charges during analysis, the sample was coated with a thin gold layer.

\section{Results and discussion \\ Mechanical properties}

The mechanical properties of the composite laminates mainly depend on elements such as the processing techniques, chemical treatment of the fibers, stacking sequence and matrix material. The test results are tabulated in Table 3. The results show that the tensile strength of laminate L3 is $55.83 \mathrm{MPa}$ and is higher among the hybrid natural fiber composite, L2 has $45.5 \mathrm{MPa}$ which 
stands next to L3 laminate. Thus by the addition of bio-nanofillers, the strength is increased by $22.5 \%$ for L3 laminate. Due to the volume of carbon fiber layers, the pure synthetic carbon fiber laminate, has a highest tensile strength of $114.67 \mathrm{MPa}$ and laminate L4 has the lowest strength of 22.97 .

Table 3 illustrates the flexural modulus and strength of the composites, having implemented the three-point bending test for assessment. Among the hybrid composite samples, L3 has the highest flexural modulus and strength of ca.10 GPa and $200 \mathrm{MPa}$ respectively. Laminate L2 gives the least flexural modulus and strength of about $3.3 \mathrm{GPa}$ and $100 \mathrm{MPa}$ respectively. Thus by the usage of fish bone nanopowder in polymer composites, the flexural modulus and strength increases tremendously and showns an increase of $200 \%$ and $100 \%$ respectively.

From Table 3, laminate L2 has the highest ILSS value compared to that of the other hybrid laminates. Laminate L4 has the lowest ILSS of 2.5 MPa. The laminate L3 has 3.13 MPa of ILSS and shows a decline of about $22 \%$ by the addition of the bio-nanofillers. On the other hand, the impact strength shows a reverse trend, the laminate L4 absorbs $3.5 \mathrm{~J}$ of impact energy before failure which is maximum among all other fabricated composite laminates. Laminate L1 has the least impact strength of $1.25 \mathrm{~J}$ while laminates L2 and L3 have an impact energy of approximately 2.5 and $2 \mathrm{~J}$ respectively

Among Phoenix Pusilla/carbon fiber hybrid composite laminate L3 has the highest hardness of about $91 \mathrm{HV}$, laminate L2 has $79 \mathrm{HV}$, and laminate L4 has $57 \mathrm{HV}$. With fish bone powder performing the function of a filler material, the test outcomes illustrated that there was a $15 \%$ increase in the value of rigidity.

Morphological Analysis 
To examine the nature of failure on the surfaces of laminates, to detect the flaws and to understand the interfacial bonding between fiber and matrix materials, the tensile fractured specimens were subjected to the SEM. Fig.2 (a) indicates marginal pull-out of fibers from the laminate L1, indicating excellent interaction between the fiber and polymers, this is reflected in the excellent tensile performance of the composites. Fig. 2 (b) shows the pull-out of carbon fibers and the natural fibers during the tensile test resulting from poor bonding between the fiber and matrix. Fig. 2 (c) indicates the equal distribution of the filler material throughout the laminate and also shows the reduction in the voids formation. Fig. 2(d) clearly shows that the equal distribution of the fillers results in the elimination of void formation. The fiber pull-out is more for laminate L4 during the tensile test, therefore posses least tensile strength but maximum impact strength. This is because delamination, fiber matrix debonding and fiber pull out is essential for better impact resistance [17].

\section{Conclusions}

The carbon/Phoenix Pusilla fabric reinforced hybrid epoxy based composite laminates has been successfully manufactured by using manual hand lay-up process, with and without the nanofiller material. In accordance with ASTM standards, testing of samples aimed to focus on their relevance and appropriateness for implementation in a range of engineering functions. The amalgamation of Phoenix Pusilla with carbon fiber can promote the enhancement of a range of mechanical features. The tensile strength, flexural strength, modulus and hardness of the laminates prepared are increased by $22.5 \%, 200 \%, 100 \%$ and $15.18 \%$ respectively for the same construction sequence with the addition of the bio-nanofillers. Laminate L4 absorbs maximum amount of impact energy before its failure compared to all other laminates. The occurrence of a reliable and stable fiber pull-out is evident within the SEM evaluations. This indicates that the 
prepared composites are good, whilst voids are at a minimum with good bonding between continuous (matrix) and discontinuous (fibers) materials. From the SEM micrographs, it is also evident that the laminates L3 and L4 demonstrate effective dispersion of the filler material/fish bone powder. It is found that the carbon/Phoenix Pusilla hybrid composite with fillers showed enhanced mechanical properties and can be utilised in various modern engineering applications.

\section{References}

[1]. Sanjay, M. R., Madhu, P., Jawaid, M., Pradeep, S., Senthamaraikannan, P., Senthil, S. 2018. Characterization and Properties of Natural Fiber Polymer Composites: A Comprehensive Review. J. Clean. Prod. 172; 566-581.

[2]. Madhu, P., Sanjay, M. R., Jawaid, M., Pradeep, S., Yogesha, B., Saba, N. 2018. Potential of natural/synthetic hybrid composites for aerospace applications. Sustainable Composites for Aerospace Applications. 315-351.

[3]. Md. Saiful Islam., Atiqah Binti Hasbullah., Mahbub Hasan., Zainal Abidin Talib., Jawaid, M., Mohamad Haafiz, M. K. 2015. Physical, mechanical and biodegradable properties of kenaf/coir hybrid fiber reinforced polymer nanocomposites. Mat, Today. 4:69-76.

[4]. Alavudeen, A., Rajini, N., Karthikeyan, S., Thiruchitrambalam, M., Venkateshwaren, N. 2015. Mechanical properties of banana/kenaf fiber-reinforced hybrid polyester composites: Effect of woven fabric and random orientation. Mat. Des. 66:246-257.

[5]. Chaudhary, V., Bajpai, P. K., Maheshwari, S. 2018. Studies on Mechanical and Morphological Characterization of Developed Jute/Hemp/Flax Reinforced Hybrid Composites for Structural Applications. J. Nat. Fib. 15: 80-97. 
[6]. Arpitha, G. R., Sanjay, M. R., Senthamaraikannan, P., Barile, C., Yogesha, B. 2017. Hybridization Effect of Sisal/Glass/Epoxy/Filler Based Woven Fabric Reinforced Composites. Exp. Tech. 6: 577-584

[7]. Sanjay, M. R., Yogesha, B. 2018. Studies on hybridization effect of jute/kenaf/E-glass woven fabric epoxy composites for potential applications: Effect of laminate stacking sequences. J. Ind. Text. 47: 1830-1848.

[8]. Arthanarieswaran, V. P., Kumaravel, A., Kathirselvam, M., Saravanakumar,S. S. 2016. Mechanical and thermal properties of Acacia leucophloea fiber/ epoxy composites: Influence of fiber loading and alkali treatment. Inter. J. Poly. Anal. Char. 21(7):571-583.

[9]. Narendar, R., Priya Dasan, K. 2013. Effect of Chemical Treatment on the Mechanical and Water Absorption Properties of Coir Pith/Nylon/Epoxy Sandwich Composites. Inter. J. Poly. Anal. Char. 18 (5): 369-376.

[10]. Ghali, L., Msahli, S., Zidi, M., Sakli, F. 2009. Effect of pre-treatment of Luffa fibers on the structural properties. Mater. Lett. 63: 61-63.

[11]. Uma Maheswari, C., Obi Reddy K., Muzenda, E., Shukla, M., Varada Rajulu, A. 2013. A Comparative Study of Modified and Unmodified High-Density Polyethylene/Borassus Fiber Composites. Inter. J. Poly. Anal. Char. 18: 439-450.

[12]. Obi Reddy, K., Uma Maheswari, C., Shukla, M., Varada Rajulu, A. 2012. Chemical composition and structural characterization of Napier grass fibers. Mater. Lett. 67: 35-38.

[13]. Manimaran, P., Senthamaraikannan, P., Sanjay, M. R., Marichelvam, M. K., Jawaid, M. 2018. Fiber Characterization of Furcraea Foetida natural Fiber as Potential Reinforcement of Bio-composite. Carbohydr. Polym. 181: 650-658. 
[14]. Gupta, A., Hari Singh., Walia, R. S. 2016. Hybrid filler composition optimization for tensile strength of jute fibre-reinforced polymer composite. Bulle. Mater. Scien. 39: 1223-1231.

[15]. Athith, D., Sanjay, M. R., Yashas Gowda, T. G., Madhu, P., Arpitha, G. R., Yogesha, B., Omri, M. A. 2018. Effect of tungsten carbide on mechanical and tribological properties of jute/sisal/E-glass fabrics reinforced natural rubber/epoxy composites. J.Indus. Tex. 48: 713737.

[16]. Gupta, A., Singh, H., Walia, R. S. 2015. Effect of fillers on tensile strength of pultruded glass fiber reinforced polymer composite. Ind. J. Engg. Mater. Scien. 22: 62-70.

[17]. Cantwell, W.J., Morton, J. 1991. The impact resistance of composite materials---a review, Compos. 22: 347-362. 
Table 1. Properties of carbon fiber and Phoenix Pusilla plant leaves fiber.

\begin{tabular}{|c|c|c|c|}
\hline \multicolumn{2}{|c|}{ Property } & Carbon fiber & Phoenix Pusilla fiber \\
\hline \multicolumn{2}{|c|}{ Type } & Woven fabrics & Mat \\
\hline \multicolumn{2}{|c|}{ Density $(\mathrm{gm} / \mathrm{cc})$} & 1.8 & 2.2 \\
\hline \multicolumn{2}{|c|}{ Weight (gsm) } & 200 & 380 \\
\hline \multicolumn{2}{|c|}{ Tensile strength (MPa) } & 3500 & $350-380$ \\
\hline \multicolumn{2}{|c|}{ Youngs modulus (GPa) } & 230 & 2.8 \\
\hline \multicolumn{2}{|c|}{ Warp yarns (yarns $/ \mathrm{m})$} & 810 & 95 \\
\hline \multicolumn{2}{|c|}{ Weft yarns(yarns/m) } & 810 & 75 \\
\hline \multirow{2}{*}{$\begin{array}{l}\text { Orientation } \\
\text { (Angle) }\end{array}$} & Horizontal (Weft) & $90^{\circ}$ & $30^{\circ}$ \\
\hline & Vertical (Warp) & $0^{0}$ & $60^{\circ}$ \\
\hline
\end{tabular}

Table 2. Schematic and pictorial view of the fabricated laminates.

\begin{tabular}{|c|c|c|c|c|}
\hline Laminate & L1 & L2 & L3 & L4 \\
\hline \multirow{5}{*}{$\begin{array}{l}\text { Schematic } \\
\text { representation }\end{array}$} & Carbon Fiber & Carbon Fiber & Carbon Fiber & Phoenix Pusilla \\
\hline & Carbon Fiber & Phoenix Pusilla & Phoenix & Carbon Fiber \\
\hline & Carbon Fiber & Carbon Fiber & Pusilla & Phoenix Pusilla \\
\hline & Carbon Fiber & & Carbon Fiber & \\
\hline & ${ }^{*} \mathrm{C}+\mathrm{C}+\mathrm{C}+\mathrm{C}$ & ${ }^{*} \mathrm{C}+\mathrm{P}+\mathrm{C}$ & ${ }^{*} \mathrm{C}+\mathrm{P}+\mathrm{C}+$ Filler & $* \mathrm{P}+\mathrm{C}+\mathrm{P}+$ Filler \\
\hline Nano & $0 \%$ & $0 \%$ & $4 \%$ & $4 \%$ \\
\hline filler & & & & \\
\hline
\end{tabular}




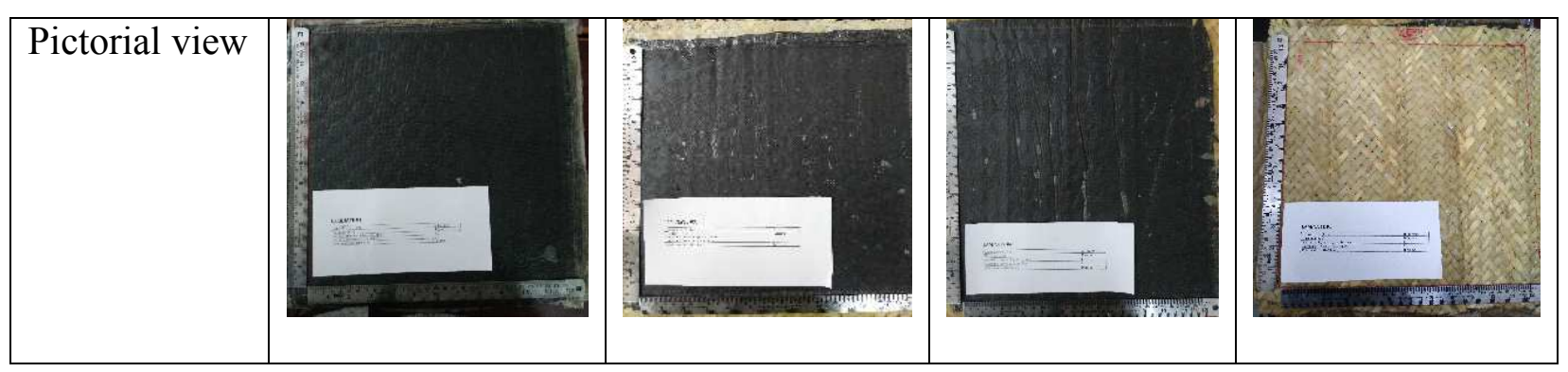

Table 3. Mechanical properties of the Phoenix Pusilla/carbon fiber reinforced composites.

\begin{tabular}{|c|c|c|c|c|c|c|}
\hline Laminate & Tensile & Flexural & Flexural & ILSS & Impact & Hardness \\
& strength & Modulus & strength & $(\mathrm{MPa})$ & strength & $(\mathrm{HV})$ \\
& $(\mathrm{MPa})$ & $(\mathrm{GPa})$ & $(\mathrm{MPa})$ & & & \\
& & & & & & \\
\hline L1 & 114.67 & 28.70 & 286.88 & 6.25 & 1.25 & 103 \\
\hline L2 & 45.59 & 3.31 & 101.25 & 4.00 & 2.5 & 79 \\
\hline L3 & 55.83 & 9.72 & 202.5 & 3.13 & 2 & 91 \\
\hline L4 & 22.97 & 4.37 & 151.88 & 2.5 & 3.5 & 57 \\
\hline
\end{tabular}




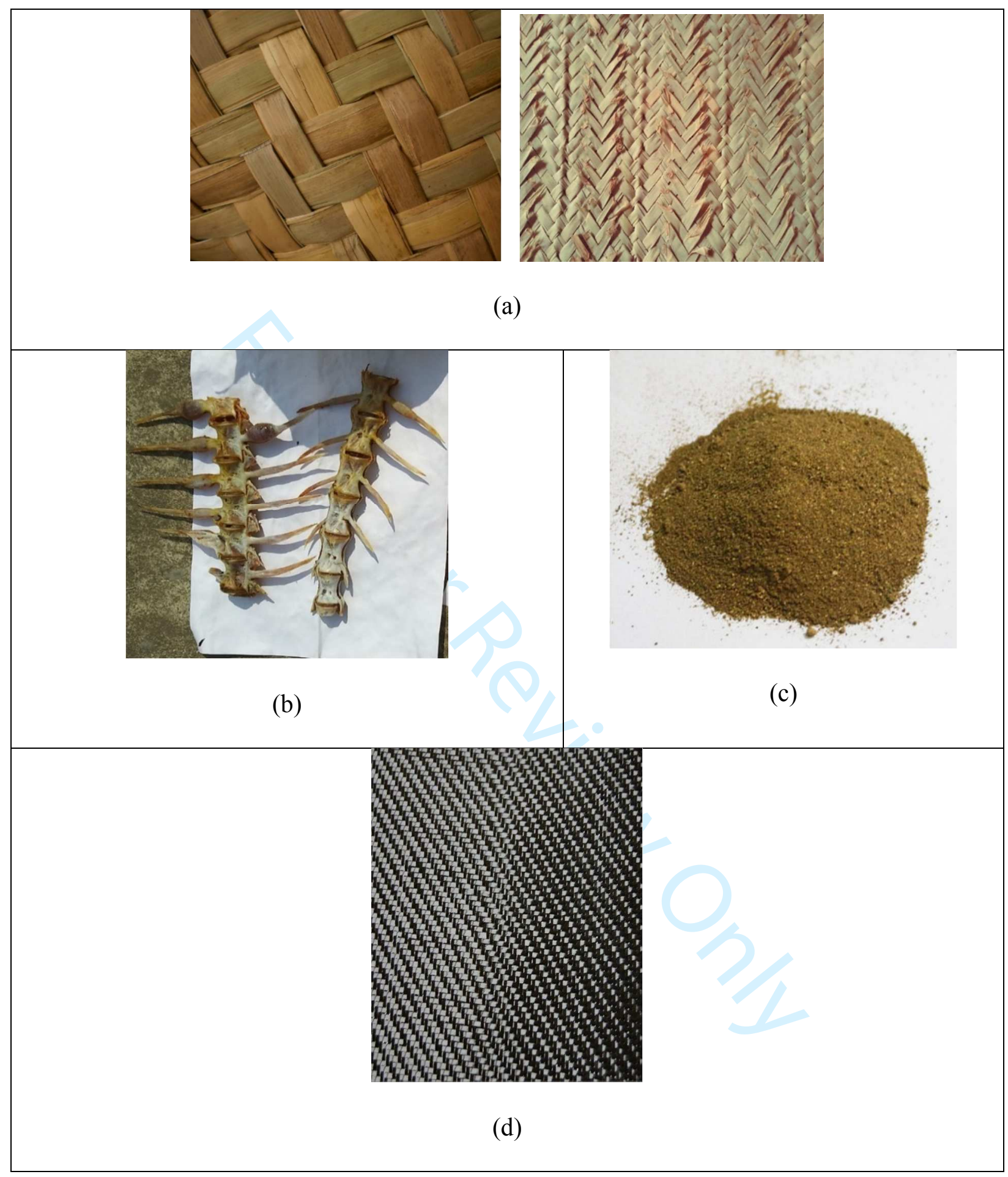

(a)

(b)

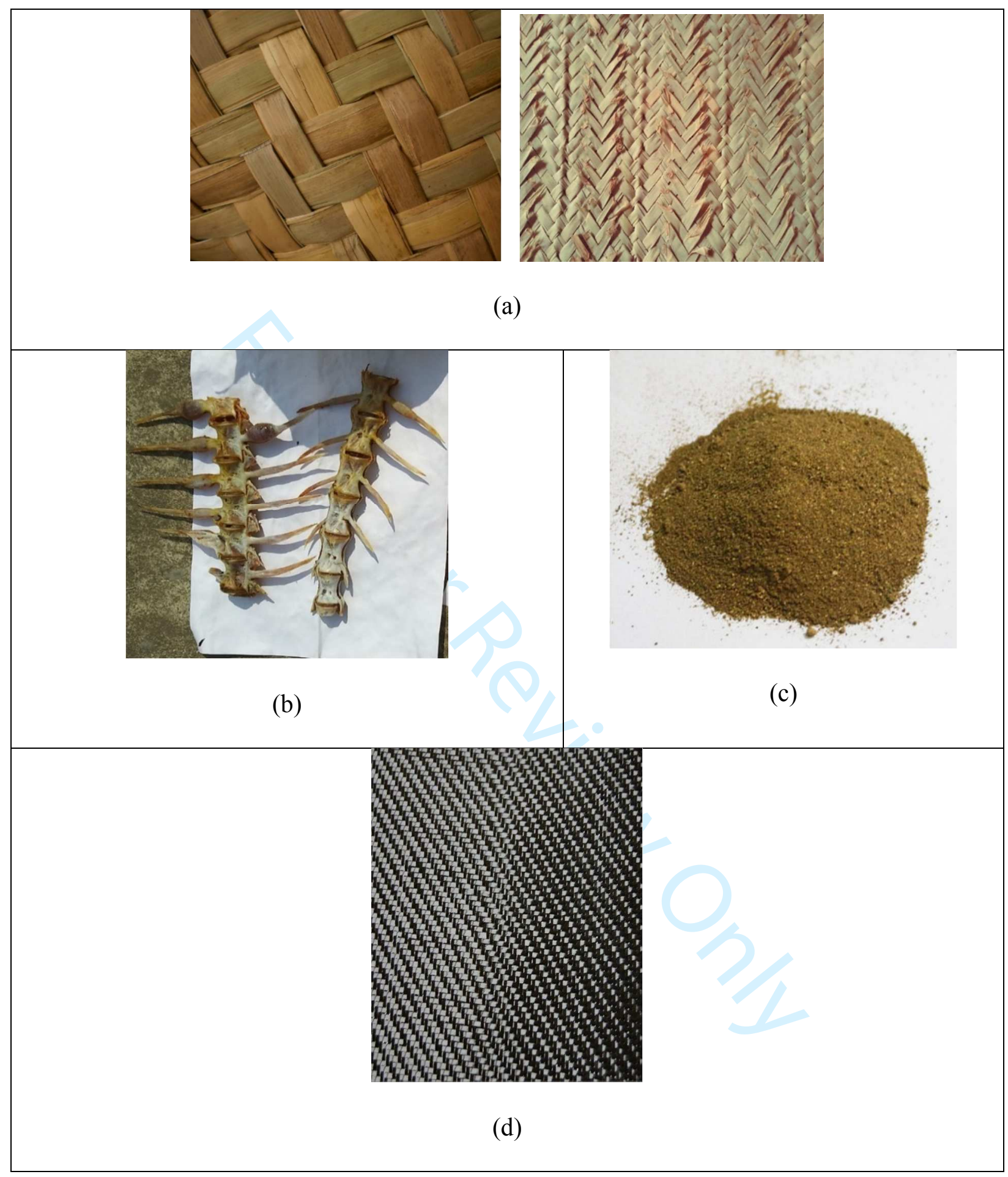

Figure 1. (a) Prepared mats from Phoenix Pusilla plant leaves front and rare side, (b) fish bone, (c) fish bone filler and (d) carbon fiber mat. 


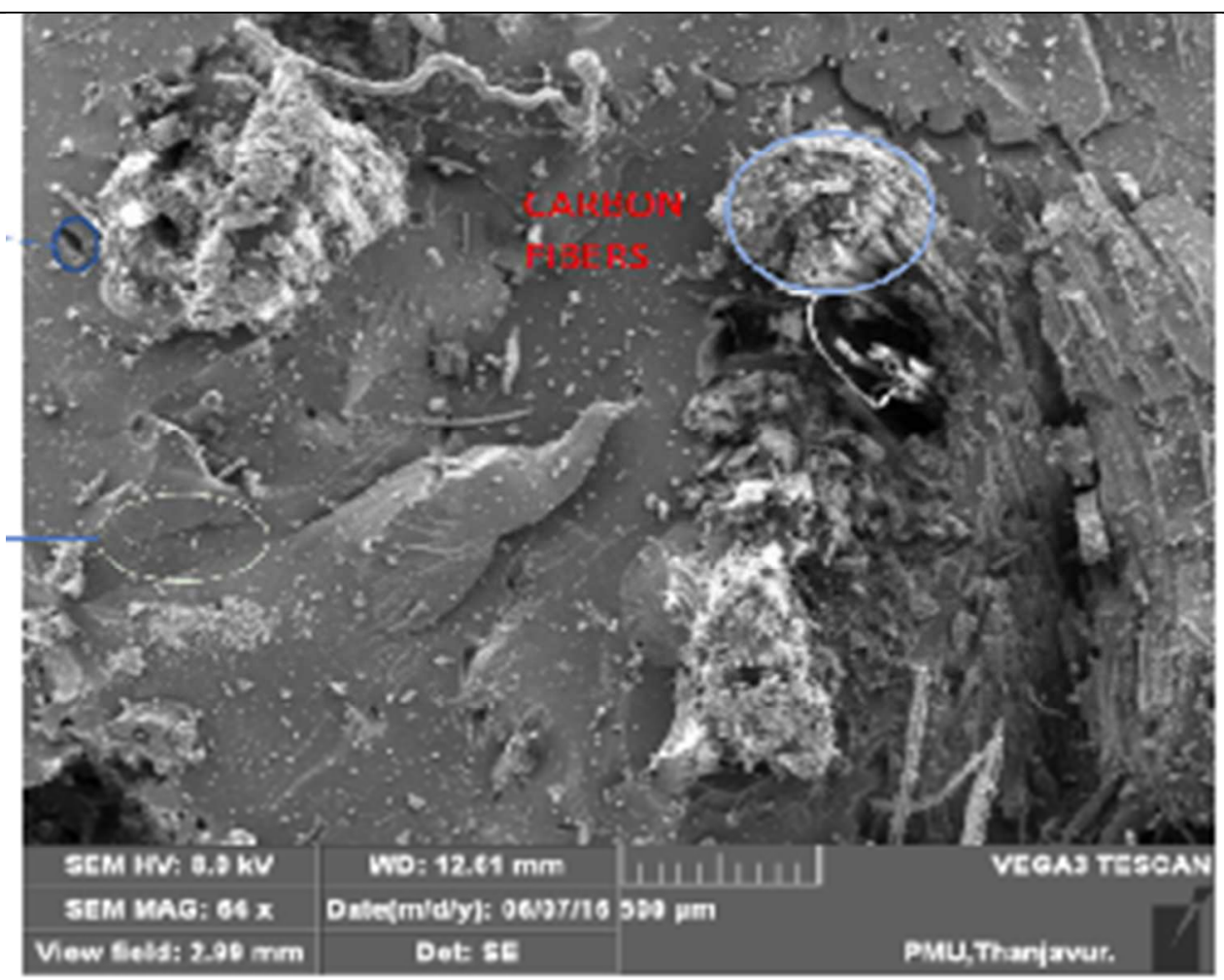

(a)

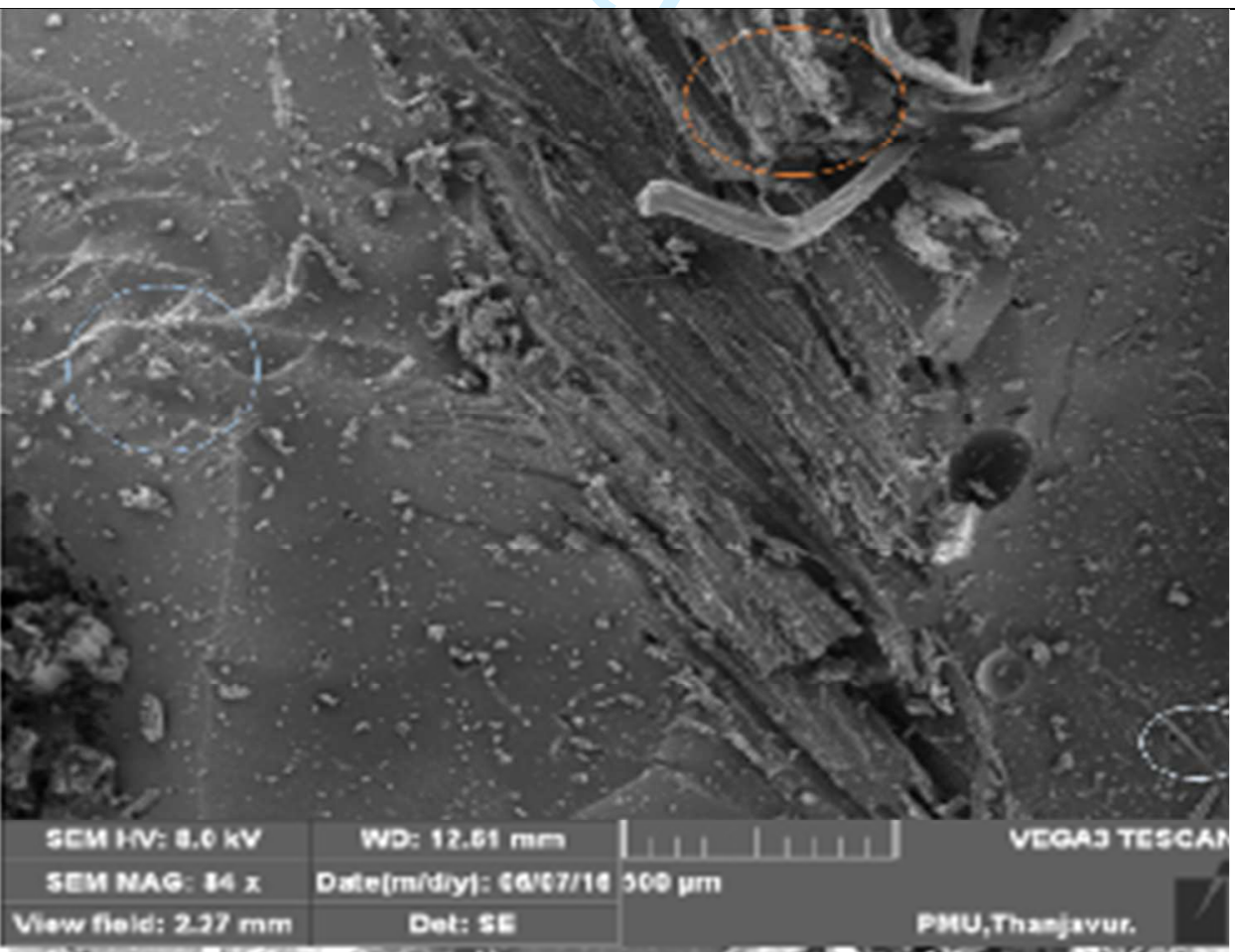

(b) 


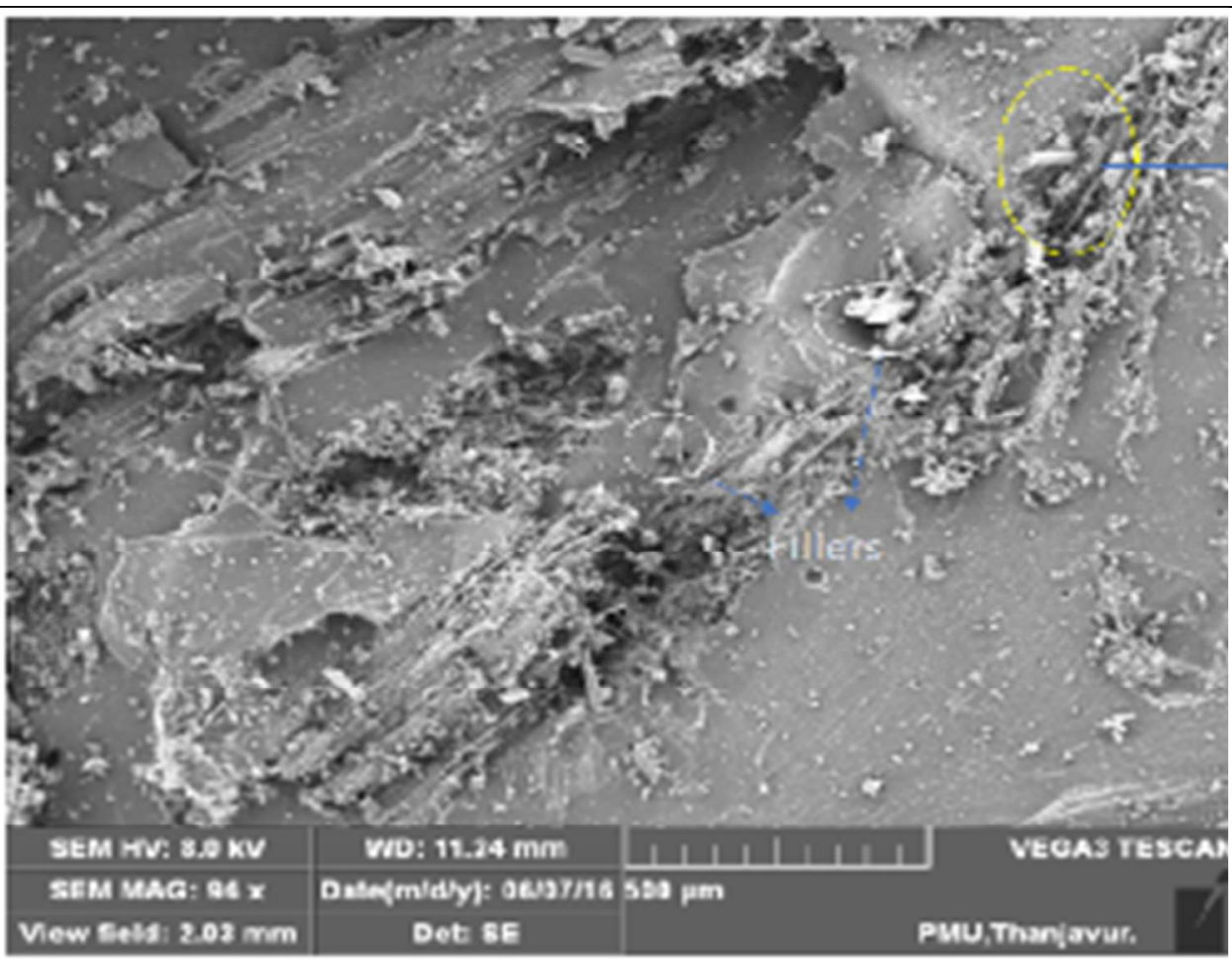

(c)

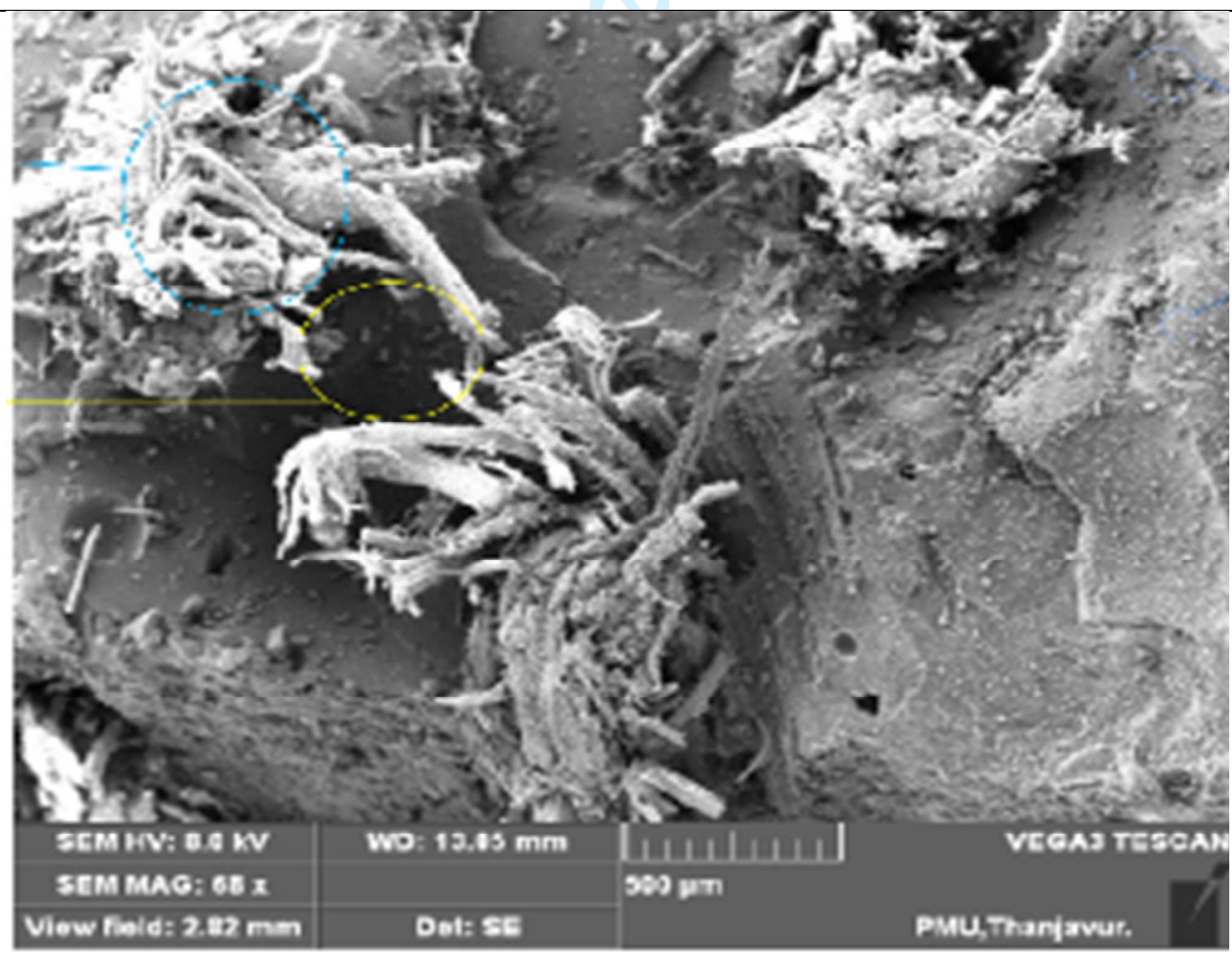

(d) 
Figure 2. SEM images of the failure specimens of tensile test (a) carbon fiber, fiber pull-out and voids (L1), (b) matrix material (L2), (c) fillers, natural fiber (L3) and (d) filler material, fiber/matrix interface (L4). 